\title{
Homeobox Transcription Factor Prox1 in Sympathetic Ganglia of Vertebrate Embryos: Correlation With Human Stage 4s Neuroblastoma
}

\author{
JÜRGEN BECKER, BAIGANG WANG, HELENA PAVLAKOVIC, KERSTIN BUTTLER, AND JÖRG WILTING
}

Department of Anatomy and Cell Biology, University Medicine Goettingen, 37075 Goettingen, Germany

\begin{abstract}
Previously, we observed expression of the homeobox transcription factor Prox 1 in neuroectodermal embryonic tissues. Besides essential functions during embryonic development, Prox1 has been implicated in both progression and suppression of malignancies. Here, we show that Prox 1 is expressed in embryonic sympathetic trunk ganglia of avian and murine embryos. Prox 1 protein is localized in the nucleus of neurofilament-positive sympathetic neurons. Sympathetic progenitors represent the cell of origin of neuroblastoma (NB), the most frequent solid extracranial malignancy of children. NB may progress to life-threatening stage 4 , or regress spontaneously in the special stage $4 \mathrm{~s}$. By qRT-PCR, we show that Prox 1 is expressed at low levels in 24 human NB cell lines compared with human lymphatic endothelial cells (LECs), whereas equal immunostaining of nuclei can be seen in embryonic LECs and sympathetic neurons. In NB stages 1, 2, 3, and 4, we observed almost equal expression levels, but significantly higher amounts in stage 4s NB. By immunohistochemistry, we found variable amounts of Prox 1 protein in nuclei of NB cells, showing intra and interindividual differences. Because stage $4 \mathrm{~s} \mathrm{NB}$ are susceptible to postnatal apoptosis, we assume that high Prox 1 levels are critical for their behavior. (Pediatr Res 68: 112-117, 2010)
\end{abstract}

$\mathrm{T}^{\mathrm{s}}$ he homeobox transcription factor Prox 1 is an essential regulator of organ development in vertebrate embryos. It is expressed in specific compartments of all three germ layers (1-3). Prox 1 null mice die during early stages of development (4). Prox 1 has a great impact on the development and maintenance of the lymphovascular system $(4,5)$, liver and pancreas rudiments $(6,7)$, lens and retina $(3,8)$, and the heart $(9)$. In recent years, several studies have linked the loss of Prox 1 functions to tumor progression. In hematologic malignancies and solid cancers, DNA and RNA mutations of PROX1 have been found $(10,11)$. Decreased PROX1 expression has been observed in progressed pancreatic and hepatocellular carcinoma $(12,13)$ and transcriptional silencing by hypermethylation of the PROX1 gene has been found in breast cancer (14). In contrast, a recent study reports that PROX1 enhances colorectal cancer progression (15).

Although Prox 1 expression has been observed in neuroectodermal cells of avian and murine embryos $(2,16)$, and very recently in retinoblastoma (17), its possible functions during

Received November 24, 2009; accepted April 18, 2010.

Correspondence: Jörg Wilting, Ph.D., Universitymedicine Goettingen, Department of Anatomy and Cell Biology, Kreuzbergring 36, 37075 Goettingen, Germany; e-mail: joerg.wilting@med.uni-goettingen.de

Supported by grant Wi1452/11-1 from Deutsche Forschungsgemeinschaft. progression of tumors derived from these tissues has not been investigated. We have studied Prox 1 expression in the sympathetic nervous system of avian and murine embryos, and in childhood tumors derived from this tissue: neuroblastoma (NB). We show that Prox1 is expressed in sympathetic neurons during early stages of development at similar levels as in lymphatic endothelial cells (LECs), but at greatly reduced levels in human NB cell lines. Studies of primary NB of all stages (stages 1-4s) show significantly higher amounts of Prox $1 \mathrm{mRNA}$ in stage $4 \mathrm{~s}$. Since stage $4 \mathrm{~s}$ has a high incidence of spontaneous regression, our results indicate a suppressive function for Prox1 in NB.

\section{METHODS}

Animals. Fertilized chick and quail eggs were incubated at $37.8^{\circ} \mathrm{C}$ and $80 \%$ humidity. Staging of embryos was performed according to Hamburger and Hamilton (18). Day 3 to day 6 embryos were studied. NMRI mouse embryos from embryonic day (ED) 10-13.5 were studied. Embryos were removed from the uterus and remained either unfixed or were fixed in $4 \%$ paraformaldehyde (PFA) for $15 \mathrm{~min}$. The Animal Care and Use Committee of the University Medicine Goettingen was informed about the study. ${ }^{1}$

Primary NBs. RNA samples of 50 primary, untreated tumors were kindly provided by the Tumorbank of the German Neuroblastoma Studies Group, Children's Hospital University Cologne, Germany. Specimens were prepared according to a standard protocol. Two representative areas were dissected out of the tumor and each was divided into four parts. One part was fixed in fomalin and three parts were snap frozen in liquid nitrogen. Snap-frozen specimens were used for RNA isolation with Trizol (Invitrogen, Carlsbad, CA). Samples were tested with Bioanalyzer 2100 (Agilent Technologies, Böblingen, Germany). One sample was discarded. The remaining 49 samples were allocated to the NB stages as follows: stage $1(n=8)$, stage $2(n=6)$, stage $3(n=5$; two were $M Y C N$-amplified), stage $4(n=20 ; 10$ were $M Y C N$-amplified), and stage 4s $(n=10$; one was $M Y C N$-amplified).

Immunofluorescence of cryosections. Mouse and quail embryos were embedded in Tissue Freeze Medium (Sakura Finetek Europe, NL). Cryosections of $16-\mu \mathrm{m}$ thickness were prepared. The following primary antibodies were used for double staining: monoclonal QH1 antibody (against quail endothelial cells; 1:100; Developmental Studies Hybridoma Bank, IA), ratanti-mouse CD31/PECAM-1 (1:50; BD Pharmingen, San Diego, CA), rabbitanti-human Prox1 (1:750; Reliatech, Wolfenbüttel, Germany), mouse antihuman neurofilament (1:100, Dako, Hamburg, Germany). Sections were incubated with the primary antibodies overnight. In the negative controls, the primary antibodies were omitted. Typical controls have been published previously (19). Secondary Alexa 488-conjugated goat-anti-rat IgG, Alexa 594-conjugated goat-anti-mouse IgG, Alexa 488-conjugated goat-anti-rabbit $\mathrm{IgG}$, and Alexa 594-conjugated goat-anti-rabbit IgG (Molecular Probes,

Abbreviations: ED, embryonic day; ISH, in situ hybridization; LEC, lymphatic endothelial cell(s); NB, neuroblastoma; PFA, paraformaldehyde; PCNA, proliferating cell nuclear antigene; Prox1, prospero-related homeobox transcription factor-1; TH, tyrosine hydroxylase 
Eugene, OR) were applied at 1:200. Sections were viewed with Zeiss Axio Imager Z1 (Zeiss, Göttingen, Germany).

Immunohistology of paraffin sections. Formalin-fixed primary NBs were dehydrated and embedded in paraffin. Sections of 7- $\mu$ m thickness were prepared. After deparaffination, nonspecific binding of antibodies was blocked with $1 \%$ BSA. For antigen retrieval, slides were incubated in citrate buffer $(\mathrm{pH} 6)$ and boiled in a microwave $(5 \times 5 \mathrm{~min}$ at $600 \mathrm{~W})$. After rinsing, sections were incubated for $10 \mathrm{~min}$ at $37^{\circ} \mathrm{C}$ with $0.1 \%$ pepsin solution (Sigma Chemical Co., Deisenhofen, Germany). Primary antibodies were rabbit-antihuman Prox1 (1:300; Reliatech) and mouse anti-human neurofilament (1:50, Dako). Secondary antibodies were either peroxidase-conjugated goat-antirabbit IgG (1:100, Sigma Chemical Co.) to detect Prox1 or Alexa 488conjugated goat-anti-rabbit IgG, and Alexa 594-conjugated goat-anti-mouse IgG (1:100, Molecular Probes) for double immunofluorescence. DAB was used as chromogen for peroxidase reaction, and slides were counter stained with nuclear fast red.

In situ hybridization (ISH). For ISH of whole embryos, specimens were fixed in 4\% PFA, rinsed, dehydrated in 100\% methanol, and frozen. They were rehydrated, treated with proteinase $\mathrm{K}$, rinsed, and postfixed with $4 \%$ PFA. ISH was performed at $70^{\circ} \mathrm{C}$ overnight. For detection of cProx 1 mRNA, a chick probe was used as described (3). Linearization was performed with EcoRI (T3) and SacI (T7) for the preparation of sense and anti-sense probes, respectively. Expression of tyrosine hydroxylase $(\mathrm{TH})$ was studied with a quail probe described previously (20). The coding region (nucleotide 180 1137) was cloned into pGEM-3 and a $350 \mathrm{bp}$ anti-sense probe was prepared with HindIII (T7). For double ISH, we stained Prox1 in blue and the endothelial marker Tie2 in red. A chick Tie2 probe was used as described (21). Linearization was performed with XhoI (T7) and NotI (T3) for the preparation of fluorescein-labeled sense and anti-sense probes, respectively. Specimens were rinsed and incubated with alkaline phosphatase-conjugated anti-digoxigenin (1:2000) and anti-fluorescein (1:3000) antibodies in a blocking agent (Roche). The antibodies were detected with Fast Red and BCIP/ NBT in alkaline phosphatase buffer. The first reaction was stopped by heat inactivation and the second with $1 \mathrm{mM}$ EDTA in PBT. Specimens were cleared in dimethyl-formamide and stored in 4\% PFA.

Cell culture. We studied 24 human NB cell lines: CHLA 20, CHLA90, CHP100, CHP134, GI-MEN, IMR5, IMR32, KCN, Kelly, LAN1, LAN2, LAN5, LAN6, NB69, NBLS, NGP, NLF, NMB, SH-EP, SH-IN, SH-SY5Y, SK-N-AS, SK-N-SH, and SMS-KAN. Commercial sources and references for all cell lines are listed in (22). All cells were maintained in a humidified incubator at $37^{\circ} \mathrm{C}$ and $5 \% \mathrm{CO}_{2}$ atmosphere using RPMI 1640 medium (Lonza, Basel, Switzerland) with $10 \%$ fetal bovine serum (Biochrome, Berlin, Germany) and $1 \%$ penicillin/streptomycin (Invitrogen, Carlsbad, CA).

RNA isolation from cultured NB cells. Cells were rinsed twice with PBS, and RNA was isolated directly from the culture plate using Trizol (Invitrogen) as recommended. Quality of RNA samples was analyzed with NanoDrop spectrophotometer (NanoDrop products, Wilmington, DE) and ethidium bromide staining on agarose gels.

Real-time RT-PCR. We prepared cDNA from $2 \mu \mathrm{g}$ total RNA using Omniscript reverse transcriptase (Qiagen, Hilden, Germany). Real-time PCR was performed with Opticon2 thermal cycler (MJ Research, Waltham, MA), using SYBR green JumpStart Taq ReadyMix (Sigma Chemical Co.-Aldrich, Taufkirchen, Germany). Primers for Prox1 were designed to produce fragments, which are exon-exon spanning, to exclude amplification of genomic DNA. Prox1 primers were fwd: $5^{\prime}$-gagtgcggcgatcttcaa-3'; rev: 5'-ggtgacaatccttcctgcat-3'.

Statistical analyses. Normality tests were performed to define the distribution of variances. Consequently, parametric or nonparametric methods of analyses were chosen. The Mann-Whitney $U$ Test or the Unpaired $t$ Test were used to compare expression levels of Prox 1 between stages of localized and disseminated NB and to compare expression levels in NB with or without MYCN amplification. Statistical significance is considered at $p<0.05$. All analyses were performed using GraphPad Prism v 3.0 software (GraphPad Software, Inc., LA Jolla, CA).

\section{RESULTS}

Proxl is expressed in early embryonic sympathetic trunk ganglia. We have studied the expression of Prox 1 at RNA and protein levels in avian and murine embryos. In chick embryos, Prox1 ISH revealed expression in sympathetic trunk ganglia, which were identified by their TH expression (Fig. $1 A$ and $B$ ). Other expression domains for Prox1 such as heart, liver, pancreas, dorsal root ganglia, and ectodermal placodes have been described previously. The segmental pattern of sympa-

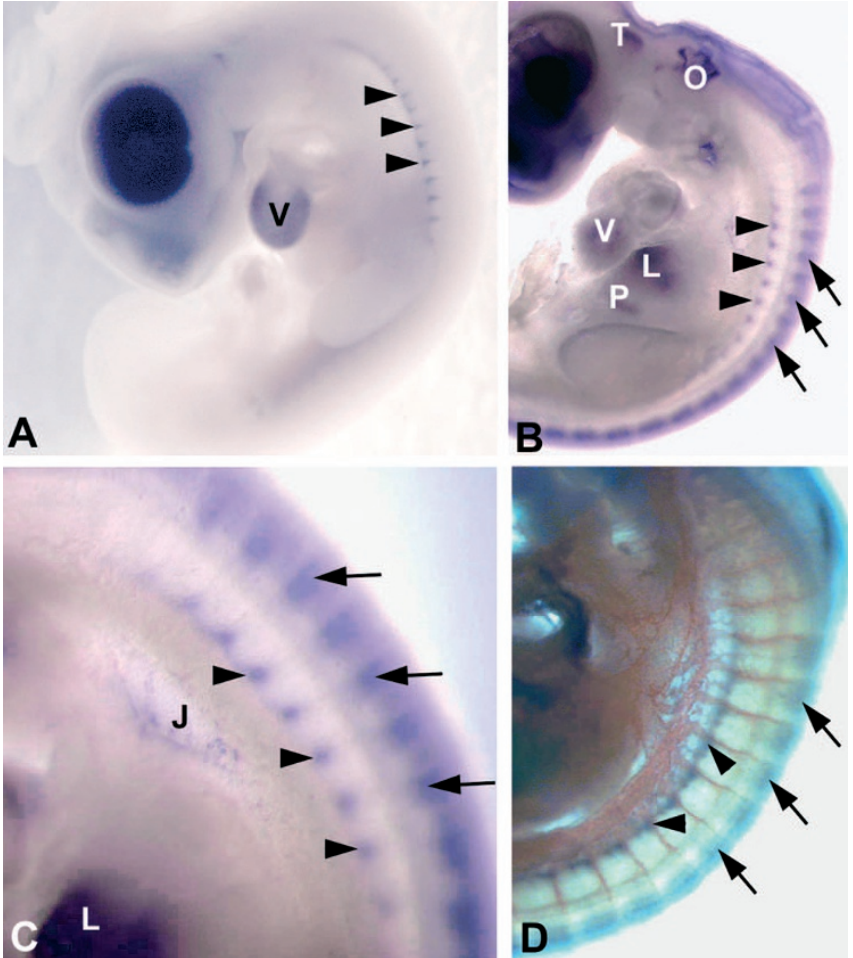

Figure 1. In situ hybridization of 4.5-d-old chick embryos with $\mathrm{TH}$ and Prox 1 probes. A) TH is expressed in the ventricle (V) of the heart and in sympathetic trunk ganglia (arrowheads). B) Expression of Prox1 in sympathetic trunk ganglia (arrowheads), dorsal root ganglia (arrows), liver (L), otic placode $(\mathrm{O})$, pancreas $(\mathrm{P})$, trigeminal ganglion $(\mathrm{T})$, cardiac ventricle $(\mathrm{V})$, and neural tube. C) Higher magnification of B). Note expression in sympathetic trunk ganglia (arrowheads), dorsal root ganglia (arrows), neural tube, lymphangiogenic jugular region (J), and liver (L). D) Double ISH showing expression of Prox1 (blue) and Tie2 (red). Note close association of sympathetic trunk ganglia (arrowheads) with the intersomitic vessels and the main vascular trunks. Dorsal root ganglia (arrows).

thetic trunk ganglia and their close association with the vascular system was evident by double ISH with Prox1 and the vessel-specific Tie2 probe (Fig. $1 C$ and $D$ ). To further analyze the spatial relationship between sympathetic trunk ganglia and blood vessels, we performed double staining of quail embryos with Prox1 and QH1 antibodies (23). Prox1 was localized in nuclei and QH1 demarcated quail endothelial cells. In stage 20 $(\mathrm{HH})$ embryos, the paravertebral localization of sympathetic trunk ganglia and their intimate association with the roof of the aorta was evident (Fig. 2). The same characteristics were found in murine embryos. We performed double immunostaining against Prox1 and the endothelial marker CD31/ PECAM-1. In ED 11.5 embryos, we observed close proximity of Prox1-positive sympathetic trunk ganglia and the roof of the dorsal aorta (Fig. 3A). In ED 12.5 embryos, the paravertebral sympathetic trunk ganglia were in close contact to both the segmental arteries and the cardinal veins (Fig. $3 B$ and $C$ ). To confirm Prox 1 expression in sympathetic ganglia, we performed staining with anti-neurofilament antibodies (Fig. $3 D$ ). Typically, Prox 1 is stably expressed in LECs of humans and vertebrates $(4,5)$, which is also demonstrated here. Of note, the expression levels of Prox 1 in LECs and in sympathetic neurons, determined by immunofluorescence, are obvi- 


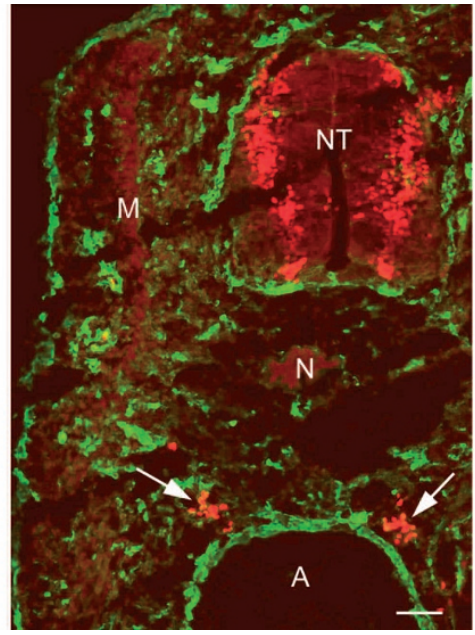

Figure 2. Transverse section of a stage $20 \mathrm{HH}$ quail embryo. Immunofluorescence staining with QH1 antibody (green) and anti-Prox1-antibodies (red). Note Prox1-positive nuclei in the neural tube (NT) and in sympathetic trunk ganglia (arrows) located close to the QH1-positive aorta (A). M, myotome; N, notochord. Bar $=60 \mu \mathrm{m}$.
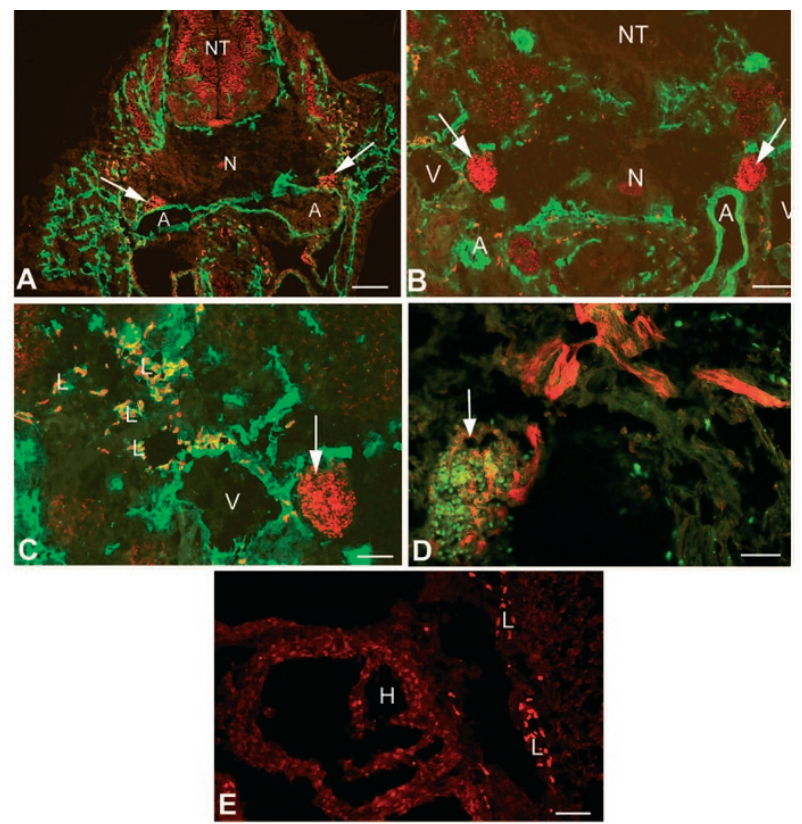

Figure 3. Transverse sections of ED 11.5 (A) and ED 12.5 (B, C) mouse embryos. Immunofluorescence staining with anti-CD31/PECAM-1 antibodies (green) and anti-Prox1-antibodies (red). A, Prox1-positive sympathetic trunk ganglia (arrows) are located at the roof of the CD31-positive dorsal aorta (A). Cells in the neural tube (NT) express Prox1. N, notochord. Bar $=150 \mu \mathrm{m} . B$, Sympathetic trunk ganglia (arrows) are located adjacent to the segmental arteries (A) and cardinal veins (V). N, notochord. Bar $=150 \mu \mathrm{m} . C$, Higher magnification of B) showing a sympathetic trunk ganglion (arrow) adjacent to a cardinal veins (V). Note that lymphatic endothelial cells (L) are Prox1 and CD31 double positive. $\mathrm{Bar}=100 \mu \mathrm{m} . D$, Transverse sections of an ED 12.5 mouse embryo stained with anti-Prox 1 (green) and anti-neurofilament antibodies $(r e d)$. Neurofilament is found in the sympathetic ganglion and the spinal nerve. Bar $=70 \mu \mathrm{m}$. $E$, Transverse sections of an ED 13.5 mouse embryo stained with anti-Prox 1 antibodies $(r e d)$. Note quantitative difference of Prox1 expression in cardiomyocytes of the embryonic heart $(\mathrm{H})$ and in lymphatic endothelial cells (L). Bar $=70 \mu \mathrm{m}$.

ously the same (Fig. 3C), whereas in cardiomyocytes lower amounts of Prox 1 can be seen in both avian (24) and murine embryos (Fig. 3E).

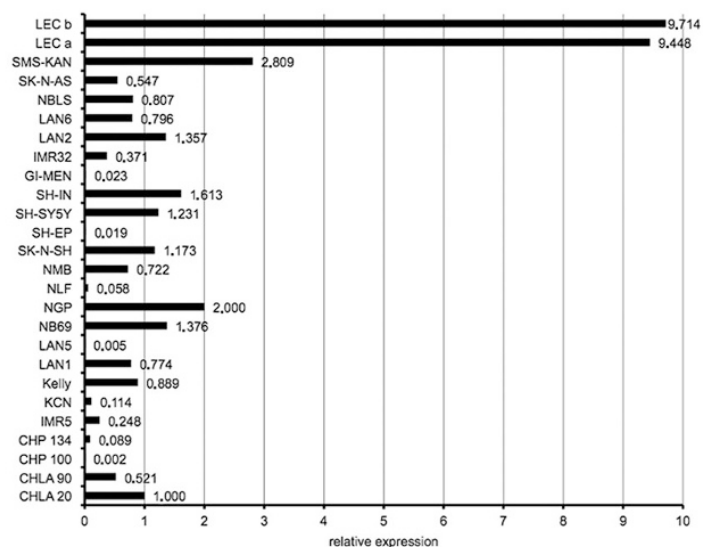

Figure 4. Expression of PROX1 in 24 human NB cell lines and lymphatic endothelial cells (LECs) as measured by real-time RT-PCR. LECs were used as positive-control because on immunohistological evaluation they express similar amounts of PROX1 as the sympathetic neurons. NB cell lines express PROX1 at significantly lower amounts than LECs.

$P R O X 1$ in NB. NB is derived from sympathoadrenal progenitor cells that migrate from the neural crest into the embryo. NB is the most frequent solid, extracranial malignancy of infants and children (25), and 5-y survival rates are $<30 \%$ in stage $4 \mathrm{NB}$. We sought to determine whether PROX1 might be related to malignant progression of $\mathrm{NB}$. We studied PROX1 at RNA levels in NB cell lines and primary tumors. We included 24 NB cell lines in our study and found expression in all of them (Fig. 4). We compared expression levels by real-time RT-PCR with human LECs, which express PROX1 (26). Expression was highly variable and significantly lower in NB cell-lines compared with LECs. Thereby, NB cells with neuronal phenotype (Kelly, SH-SY5Y) express PROX1, whereas those with epithelial phenotype (Lan-5, SH-EP) are almost negative (27). Because the immunofluorescence signal in embryos is almost the same in the nuclei of LECs and sympathetic trunk neurons, we assume down-regulation of Prox 1 in NB cell lines.

Next, we studied RNA from primary NB of stage $1(n=8)$, stage $2(n=6)$, stage $3(n=5 ; 2$ of which were $M Y C N$ amplified), stage 4 ( $n=20 ; 10$ were $M Y C N$-amplified), and stage $4 \mathrm{~s}(n=10 ; 1$ was $M Y C N$-amplified $)$. Expression levels of PROX1 were almost identical in stages $1-4$, but twice as high values were found in stage $4 \mathrm{~s}$ (Fig. 5). The difference was statistically significant $(p=0.01)$. We divided the primary tumors into two groups with normal versus amplified $M Y C N$ oncogene but did not find significant differences (data not shown). Differences could have been expected, because a MYCN binding site has been found in the $5^{\prime}$-flanking region of the PROX1 gene (28). We also studied correlations between PROX1 expression and age at diagnosis or survival of patients, but could not observe statistically significant differences.

Because PROX1 is expressed by both sympathetic neurons and LECs, we studied its expression by immunohistology in paraffin sections of primary NB (Figs. 6 and 7). PROX1 was found in the nucleus of NB cells, and in some cells also in the cytoplasm. There were groups of cells, which showed strong signals, whereas others had reduced signals or no expression 




Figure 5. Expression of PROX1 in 49 primary NB specimens. Stage $1(n=$ $8)$, stage $2(n=6)$, stage $3(n=5)$, stage $4(n=20)$, stage $4 \mathrm{~s}(n=10)$. Expression is significantly higher in stage $4 \mathrm{~s}(p=0.01)$ compared with the other four stages.

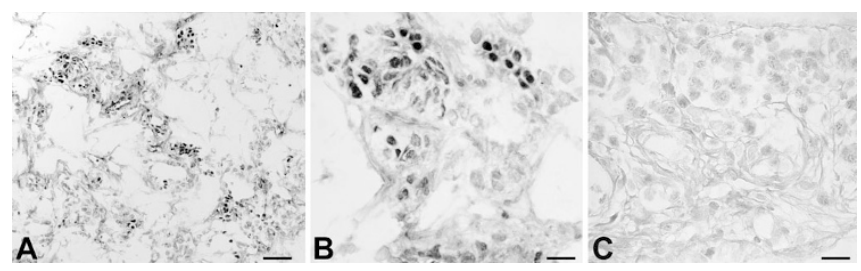

Figure 6. Anti-PROX1 staining of primary stage 4 neuroblastoma. A, Immunoperoxidase staining showing PROX1-positive nuclei. Bar $=120 \mu \mathrm{m} . B$, Higher magnification of A) showing heterogenous PROX1 expression. $C$, Negative control. Of note, most NB cells in this specimen were PROX1negative. $\mathrm{Bar}=40 \mu \mathrm{m}$ in $\mathrm{B}$ and $\mathrm{C}$.
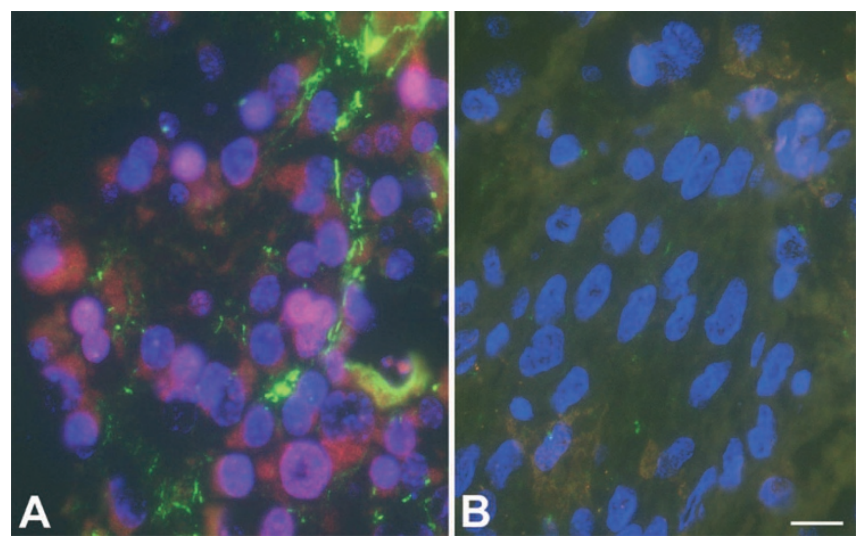

Figure 7. Immunofluorescence staining of primary stage 3 neuroblastoma. A, Anti-PROX1 (purple), anti-neurofilament (green), and Dapi (blue). PROX1 is located in the nuclei of some NB cells, and to some extent also in the cytoplasm. $B$, Negative control. Bar $=40 \mu \mathrm{m}$.

at all. Occasionally, we observed PROX1-positive lymphatics. However, LECs were very rare compared with NB cells. Therefore, our RNA data (Fig. 5) represent average expression of PROX1 in tumor cells, not LECs. Our data indicate that PROX1 is down-regulated in all NB stages, except for stage $4 \mathrm{~s}$. This might render stage $4 \mathrm{~s}$ susceptible for normal apoptosis, seen in 18-mo-old children.

\section{DISCUSSION}

Development of sympathetic neurons. Sympathetic neurons are derived from neural crest cells of the trunk. They leave the neural tube shortly after its closure. Neural crest cells follow one of three sequential pathways: along the intersomitic vessels, into the anterior sclerotome halves, and superficially beneath the epidermis. Sympathetic progenitor cells migrate both alongside the intersomitic vessels and through the sclerotomes, the latter being regulated by the repulsive guidance cue Sema3a and its receptor neuropilin-1 (29). It has been known for some time, and approved here, that sympathetic trunk ganglia develop adjacent to and controlled by the dorsal aorta. The dorsal aorta is a source of bone morphogenetic proteins (BMPs). BMP-2, BMP-4, and BMP-7 support the development of TH-positive neurons $(30,31)$. Our studies show that early clusters of sympathetic neurons, situated along the dorsal aorta, express the homeobox transcription factor Prox 1 in both avian and murine embryos. Prox 1 therefore is among the earliest DNA-binding proteins in sympathetic neurons. Only a small number of regulatory molecules have been identified in developing sympathetic ganglia, such as the vertebrate homologue of the Drosophila proneural gene achaete-scute, called MASH1 in rodents and CASH1 in avians. Once the cells are localized at the dorsal aorta they express the transcription factors Phox $2 a$ and Phox $2 b$, the bHLH protein HAND2, and the zinc finger protein GATA2 in avian embryos and GATA3 in mouse embryos (32). The functions of Prox 1 in sympathetic trunk ganglia have not been determined yet, however, its knock-down in zebrafish reduces the number of catecholaminergic neurons in the hypothalamus (33). Because Prox 1 has been linked to tumor progression, we have concentrated on $\mathrm{NB}$, an extracranial solid tumor of children, derived from sympathoadrenergic neural crest cells.

PROX1 in human malignancies. NB is derived from neural crest cells and mostly located along sympathetic trunk ganglia and in the adrenal medulla. The spectrum of the disease ranges from complete spontaneous regression (in the "special" NB stage 4s and in residual postsurgical disease in children with stage 2 tumors) to malignant progression into stage 4 , with 5-y survival rates $<30 \%$. Partial differentiation into ganglioneuroblastoma is also possible $(25,34)$. The most critical molecular predictor for the behavior and treatment of NB is the $M Y C N$ proto-oncogene. Amplification (up to $150 \times$ ) of $M Y C N$ characterizes highly aggressive tumors and poor outcome (35). Staging of NB is performed according to the International Neuroblastoma Staging System (INSS). Stages 1 and 2 NBs are localized tumors, which have grown across the midline in stage 2. Metastasis to regional lymph nodes and into systemic lymph nodes and bone marrow characterizes stages 3 and 4, respectively (36). The most enigmatic is stage $4 \mathrm{~s}$ NB. Its incidence for spontaneous regression is $10-100$ times higher than for any other human tumor (34). Regression usually takes place over 6-12 mo. Older hypotheses to explain this phenomenon were immunologic attack on the tumor and spontaneous maturation. But because the tumors disappear without any trace, these hypotheses have been replaced by the idea that apoptosis is delayed in stage 4s NB (34). Apoptosissuppressing protein BCL-2 has been found in $M Y C N$ amplified NB (37). In gene microarray analyses of stage $4 \mathrm{~s}$ $\mathrm{NB}$, up-regulation of transcription factors NFYA, HMGB1 (HBP1) and PBX3 has been detected (38). In addition, our 
data suggest a function for PROX1 (localized on chromosome 1q32) in stage $4 \mathrm{~s}$ NB. We observed variable expression of PROX1 in nuclei and cytoplasm of primary NB. Thereby, some clusters of NB cells were strongly positive, some were weakly positive and others were negative. Thereby, our quantification of PROX1 RNA in primary NB clearly represents the amount of PROX1 in NB cells proper, because the number of PROX1-positive lymphatics associated with the tumors seemed to be too small to influence the result. Our main finding is the significantly higher expression of PROX1 in stage $4 \mathrm{~s}$ NB.

A function for Prox1 as tumor suppressor has been described previously. Decreased expression levels have been found in hepatocellular and pancreatic carcinoma $(12,13)$, which may be due to epigenetic silencing. Hypermethylation of the PROXI gene has been found in breast cancer and lymphomas and in brain metastases of breast cancer $(10,14)$. Mutations of PROXI and loss of heterozygosity have been found in various cancers $(10,11,28,39)$. Whereas most studies point to a tumor suppressor function of PROX1, a recent study reports that it enhances colorectal cancer progression (15). Thereby, PROX1 marks the transition from benign colon adenoma to carcinoma in situ. Similarly, expression of PROX1 has been found in cholangiocellular carcinoma (28), whereas normal bile duct epithelial cells are negative (40). In general, it seems that PROX1 may function as a tumor suppressor in cells that normally express this gene, whereas in cells that do not express PROXI, its occurrence can be related to tumor progression. This dual function may reside in the fact that $P R O X 1$ interacts with molecules that interfere with both proliferation and differentiation. The prospero domain of Prox 1 interacts with the proliferating cell nuclear antigene (PCNA) and binds the $\beta$ B1-crystallin promoter (in lens fibers) (41). PCNA thereby reduces binding to the promoter. In hepatoblasts, Prox 1 down-regulates fibroblast growth factors and up-regulates matrix metalloproteinase 2 (42), again suggesting that it may have tumor-inhibiting or promoting functions. Interactions of Prox 1 with apoptosis-regulating genes need to be studied in future. In summary, our data show that Prox 1 is an early embryonic marker of sympathetic ganglia. High expression correlates with stage $4 \mathrm{~s}$ $\mathrm{NB}$, which has a favorable prognosis.

Acknowledgments. We thank Mrs. S. Schwoch, Mrs. Ch. Zelent, Mr. B. Manshausen, Mr. M. Winkler, and Mr. F. Ludewig for their excellent technical assistance; and Drs. F. Berthold, B. Hero, and J. Theissen (German Neuroblastoma Studies Group, Children's Hospital University Cologne, Cologne, Germany) for providing tumor samples and data.

\section{REFERENCES}

1. Oliver G, Sosa-Pineda B, Geisendorf S, Spana EP, Doe CQ, Gruss P 1993 Prox 1, a prospero-related homeobox gene expressed during mouse development. Mech Dev 44:3-16

2. Rodriguez-Niedenfuhr M, Papoutsi M, Christ B, Nicolaides KH, von Kaisenberg CS, Tomarev SI, Wilting J 2001 Prox 1 is a marker of ectodermal placodes, endodermal compartments, lymphatic endothelium and lymphangioblasts. Anat Embryol (Berl) 204:399-406

3. Tomarev SI, Sundin O, Banerjee-Basu S, Duncan MK, Yang JM, Piatigorsky J 1996 Chicken homeobox gene Prox 1 related to Drosophila prospero is expressed in the developing lens and retina. Dev Dyn 206:354-367

4. Wigle JT, Oliver G 1999 Prox 1 function is required for the development of the murine lymphatic system. Cell 98:769-778
5. Wilting J, Papoutsi M, Christ B, Nicolaides KH, von Kaisenberg CS, Borges J, Stark GB, Alitalo K, Tomarev SI, Niemeyer C, Rossler J 2002 The transcription factor Prox1 is a marker for lymphatic endothelial cells in normal and diseased human tissues. FASEB J 16:1271-1273

6. Sosa-Pineda B, Wigle JT, Oliver G 2000 Hepatocyte migration during liver development requires Prox1. Nat Genet 25:254-255

7. Wang J, Kilic G, Aydin M, Burke Z, Oliver G, Sosa-Pineda B 2005 Prox 1 activity controls pancreas morphogenesis and participates in the production of "secondary transition" pancreatic endocrine cells. Dev Biol 286:182-194

8. Wigle JT, Chowdhury K, Gruss P, Oliver G 1999 Prox 1 function is crucial for mouse lens-fibre elongation. Nat Genet 21:318-322

9. Risebro CA, Searles RG, Melville AA, Ehler E, Jina N, Shah S, Pallas J, Hubank M, Dillard M, Harvey NL, Schwartz RJ, Chien KR, Oliver G, Riley PR 2009 Prox1 maintains muscle structure and growth in the developing heart. Development 136:495-505

10. Nagai H, Li Y, Hatano S, Toshihito O, Yuge M, Ito E, Utsumi M, Saito H, Kinoshita T 2003 Mutations and aberrant DNA methylation of the PROX1 gene in hematologic malignancies. Genes Chromosomes Cancer 38:13-21

11. Takahashi M, Yoshimoto T, Shimoda M, Kono T, Koizumi M, Yazumi S, Shimada Y, Doi R, Chiba T, Kubo H 2006 Loss of function of the candidate tumor suppressor prox1 by RNA mutation in human cancer cells. Neoplasia 8:1003-1010

12. Schneider M, Buchler P, Giese N, Giese T, Wilting J, Buchler MW, Friess H 2006 Role of lymphangiogenesis and lymphangiogenic factors during pancreatic cancer progression and lymphatic spread. Int J Oncol 28:883-890

13. Shimoda M, Takahashi M, Yoshimoto T, Kono T, Ikai I, Kubo H 2006 A homeobox protein, prox1, is involved in the differentiation, proliferation, and prognosis in hepatocellular carcinoma. Clin Cancer Res 12:6005-6011

14. Versmold B, Felsberg J, Mikeska T, Ehrentraut D, Kohler J, Hampl JA, Rohn G, Niederacher D, Betz B, Hellmich M, Pietsch T, Schmutzler RK, Waha A 2007 Epigenetic silencing of the candidate tumor suppressor gene PROX1 in sporadic breast cancer. Int J Cancer 121:547-554

15. Petrova TV, Nykanen A, Norrmen C, Ivanov KI, Andersson LC, Haglund C, Puolakkainen P, Wempe F, von Melchner H, Gradwohl G, Vanharanta S, Aaltonen LA, Saharinen J, Gentile M, Clarke A, Taipale J, Oliver G, Alitalo K 2008 Transcription factor PROX1 induces colon cancer progression by promoting the transition from benign to highly dysplastic phenotype. Cancer Cell 13:407-419

16. Wigle JT, Harvey N, Detmar M, Lagutina I, Grosveld G, Gunn MD, Jackson DG, Oliver G 2002 An essential role for Prox 1 in the induction of the lymphatic endothelial cell phenotype. EMBO J 21:1505-1513

17. Balla MM, Vemuganti GK, Kannabiran C, Honavar SG, Murthy R 2009 Phenotypic characterization of retinoblastoma for the presence of putative cancer stem-like cell markers by flow cytometry. Invest Ophthalmol Vis Sci 50:1506-1514

18. Hamburger V, Hamilton H 1951 A series of normal stages in development of the chick embryo. J Morphol 88:49-92

19. Buttler K, Kreysing A, von Kaisenberg CS, Schweigerer L, Gale N, Papoutsi M, Wilting J 2006 Mesenchymal cells with leukocyte and lymphendothelial characteristics in murine embryos. Dev Dyn 235:1554-1562

20. Ziller C, Mirabel MA, Vandenbunder B, Fauquet M 1994 The tyrosine hydroxylase gene is expressed in endoderm and pancreas of early quail embryos. Anat Embryol (Berl) 189:307-315

21. Jones PF, McClain J, Robinson DM, Sato TN, Yancopoulos GD 1998 Identification and characterisation of chicken cDNAs encoding the endothelial cell-specific receptor tyrosine kinase Tie2 and its ligands, the angiopoietins. Angiogenesis 2:357-364

22. Becker J, Pavlakovic H, Ludewig F, Wilting F, Weich HA, Albuquerque R, Ambati J, Wilting J 2010 Neuroblastoma progression correlates with downregulation of the lymphangiogenesis inhibitor sVEGFR-2. Clin Cancer Res 16:1431-1441

23. Pardanaud L, Altmann C, Kitos P, Dieterlen-Lievre F, Buck CA 1987 Vasculogenesis in the early quail blastodisc as studied with a monoclonal antibody recognizing endothelial cells. Development 100:339-349

24. Wilting J, Buttler K, Schulte I, Papoutsi M, Schweigerer L, Manner J 2007 The proepicardium delivers hemangioblasts but not lymphangioblasts to the developing heart. Dev Biol 305:451-459

25. Maris JM, Hogarty MD, Bagatell R, Cohn SL 2007 Neuroblastoma. Lancet 369:2106-2120

26. Norgall S, Papoutsi M, Rossler J, Schweigerer L, Wilting J, Weich HA 2007 Elevated expression of VEGFR-3 in lymphatic endothelial cells from lymphangiomas. BMC Cancer 7:105

27. Ciccarone V, Spengler BA, Meyers MB, Biedler JL, Ross RA 1989 Phenotypic diversification in human neuroblastoma cells: expression of distinct neural crest lineages. Cancer Res 49:219-225

28. Dudas J, Mansuroglu T, Moriconi F, Haller F, Wilting J, Lorf T, Fuzesi L, Ramadori G 2008 Altered regulation of Prox1-gene-expression in liver tumors. BMC Cancer 8:92

29. Schwarz Q, Maden CH, Vieira JM, Ruhrberg C 2009 Neuropilin 1 signaling guides neural crest cells to coordinate pathway choice with cell specification. Proc Natl Acad Sci USA 106:6164-6169

30. Reissmann E, Ernsberger U, Francis-West PH, Rueger D, Brickell PM, Rohrer H 1996 Involvement of bone morphogenetic protein-4 and bone morphogenetic protein-7 in the differentiation of the adrenergic phenotype in developing sympathetic neurons. Development 122:2079-2088

31. Shah NM, Groves AK, Anderson DJ 1996 Alternative neural crest cell fates are instructively promoted by TGFbeta superfamily members. Cell 85:331-343

32. Howard MJ 2005 Mechanisms and perspectives on differentiation of autonomic neurons. Dev Biol 277:271-286 
33. Pistocchi A, Gaudenzi G, Carra S, Bresciani E, Del Giacco L, Cotelli F 2008 Crucial role of zebrafish prox1 in hypothalamic catecholaminergic neurons development. BMC Dev Biol 8:27

34. Pritchard J, Hickman JA 1994 Why does stage 4s neuroblastoma regress spontaneously? Lancet 344:869-870

35. Westermann F, Schwab M 2002 Genetic parameters of neuroblastomas. Cancer Lett 184:127-147

36. Brodeur GM, Pritchard J, Berthold F, Carlsen NL, Castel V, Castelberry RP, De Bernardi B, Evans AE, Favrot M, Hedborg F 1993 Revisions of the international criteria for neuroblastoma diagnosis, staging, and response to treatment. J Clin Oncol 11:1466-1477

37. Castle VP, Heidelberger KP, Bromberg J, Ou X, Dole M, Nunez G 1993 Expression of the apoptosis-suppressing protein bcl-2, in neuroblastoma is associated with unfavorable histology and N-myc amplification. Am J Pathol 143:1543-1550

38. Benard J, Raguenez G, Kauffmann A, Valent A, Ripoche H, Joulin V, Job B, Danglot G, Cantais S, Robert T, Terrier-Lacombe MJ, Chassevent A, Koscielny S,
Fischer M, Berthold F, Lipinski M, Tursz T, Dessen P, Lazar V, Valteau-Couanet D 2008 MYCN-non-amplified metastatic neuroblastoma with good prognosis and spontaneous regression: a molecular portrait of stage 4S. Mol Oncol 2:261-271

39. Nagai H, Kinoshita T, Suzuki H, Hatano S, Murate T, Saito H 1999 Identification and mapping of novel tumor suppressor loci on $6 \mathrm{p}$ in diffuse large B-cell nonHodgkin's lymphoma. Genes Chromosomes Cancer 25:277-283

40. Dudas J, Papoutsi M, Hecht M, Elmaouhoub A, Saile B, Christ B, Tomarev SI, von Kaisenberg CS, Schweigerer L, Ramadori G, Wilting J 2004 The homeobox transcription factor Prox 1 is highly conserved in embryonic hepatoblasts and in adul and transformed hepatocytes, but is absent from bile duct epithelium. Anat Embryol (Berl) 208:359-366

41. Chen X, Patel TP, Simirskii VI, Duncan MK 2008 PCNA interacts with Prox1 and represses its transcriptional activity. Mol Vis 14:2076-2086

42. Papoutsi M, Dudas J, Becker J, Tripodi M, Opitz L, Ramadori G, Wilting J 2007 Gene regulation by homeobox transcription factor Prox 1 in murine hepatoblasts. Cell Tissue Res 330:209-220 